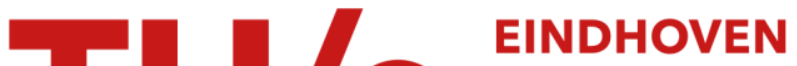 UNIVERSITY OF TECHNOLOGY
}

\section{Discrete multitone modulation for high-speed data transmission over multimode fibers using 850-nm VCSEL}

\section{Citation for published version (APA):}

Lee, S. C. J., Breyer, F., Randel, S., Cárdenas, D., Boom, van den, H. P. A., \& Koonen, A. M. J. (2009). Discrete multitone modulation for high-speed data transmission over multimode fibers using 850-nm VCSEL. In Proceedings of the 2009 Optical Fiber Communication Conference / National Fiber Optic Engineers Conference (OFC 2009 / NFOEC 2009) 24 - 26 March 2009, San Diego, CA (pp. OWM2-1/3). Institute of Electrical and Electronics Engineers.

Document status and date:

Published: 01/01/2009

\section{Document Version:}

Publisher's PDF, also known as Version of Record (includes final page, issue and volume numbers)

\section{Please check the document version of this publication:}

- A submitted manuscript is the version of the article upon submission and before peer-review. There can be important differences between the submitted version and the official published version of record. People interested in the research are advised to contact the author for the final version of the publication, or visit the $\mathrm{DOI}$ to the publisher's website.

- The final author version and the galley proof are versions of the publication after peer review.

- The final published version features the final layout of the paper including the volume, issue and page numbers.

Link to publication

\section{General rights}

Copyright and moral rights for the publications made accessible in the public portal are retained by the authors and/or other copyright owners and it is a condition of accessing publications that users recognise and abide by the legal requirements associated with these rights.

- Users may download and print one copy of any publication from the public portal for the purpose of private study or research.

- You may not further distribute the material or use it for any profit-making activity or commercial gain

- You may freely distribute the URL identifying the publication in the public portal.

If the publication is distributed under the terms of Article 25fa of the Dutch Copyright Act, indicated by the "Taverne" license above, please follow below link for the End User Agreement:

www.tue.nl/taverne

Take down policy

If you believe that this document breaches copyright please contact us at:

openaccess@tue.nl

providing details and we will investigate your claim. 


\title{
Discrete Multitone Modulation for High-Speed Data Transmission over Multimode Fibers using 850-nm VCSEL
}

\author{
S.C.J. Lee ${ }^{(1)}$, F. Breyer ${ }^{(2)}$, S. Randel ${ }^{(3)}$, D. Cárdenas ${ }^{(4)}$, H.P.A. van den Boom ${ }^{(1)}$, A.M.J. Koonen ${ }^{(1)}$ \\ (1) COBRA Research Institute, Technical University of Eindhoven, P.O. Box 513, 5600 MB, Eindhoven, the Netherlands. (2) Institute for \\ Communications Engineering, Technische Universität München, Munich, Germany. (3) Siemens AG, Corporate Technology, Information \& \\ Communications, Munich, Germany. (4) Istituto Superiore Mario Boella, Turin, Italy. E-mail: s.c.j.lee@tue.nl
}

\begin{abstract}
Gb} / \mathrm{s}$ transmission over $500 \mathrm{~m}$ and $28-\mathrm{Gb} / \mathrm{s}$ over $1 \mathrm{~km}$ of multimode fiber (with $850-$ $\mathrm{nm}$ multimode VCSEL and large-area photodetector) is experimentally demonstrated by use of discrete multitone modulation (DMT) combined with bit-loading algorithm.

(C)2009 Optical Society of America
\end{abstract}

OCIS codes: (060.2330) Fiber optics communications; (060.4080) Modulation

\section{Introduction}

By using discrete multitone modulation (DMT), it has been shown that high-speed data transmission in dispersive channels such as MMF can be possible [1-3]. Additionally, due to modulation formats like quadrature amplitude modulation (QAM), the available bandwidth can be used efficiently, allowing the use of conventional lowbandwidth MMF transceivers. Derived from the more general orthogonal frequency division multiplexing, DMT is a baseband version that is already applied in large scale in ADSL, VDSL, and powerline communication systems, proving that low-cost implementation in combination with existing MMF transceivers is possible. It is therefore a promising solution for low-cost, robust, and high capacity MMF LAN links at speeds beyond $10 \mathrm{~Gb} / \mathrm{s}$.

\section{Discrete Multitone Modulation using Bit-Loading}

An important feature of DMT is the possibility to allocate the number of bits per subcarrier according to its corresponding signal-to-noise ratio (SNR), typically known as bit-loading. Bit-loading can be divided into two categories: rate-adaptive and margin-adaptive. Rate-adaptive algorithms maximize the bit rate for a fixed bit-error ratio (BER) and given power constraint, while margin-adaptive algorithms minimize the BER for a given bit rate. In this paper, rate-adaptive bit-loading will be considered in order to maximize the transmission rate over MMF.

The algorithm of rate-adaptive bit-loading is a reformulation of the Shannon capacity formula [4] and can be expressed as a problem of maximizing the total achievable bit-rate $b$ :

$$
\max _{\mathrm{E}_{n}}(b)=\max _{\mathrm{E}_{n}}\left(\sum_{n=1}^{\hat{N}} \frac{1}{2} \log _{2}\left(1+\frac{S N R_{n}}{\Gamma}\right)\right)=\max _{\mathrm{E}_{n}}\left(\sum_{n=1}^{\hat{N}} \frac{1}{2} \log _{2}\left(1+\frac{E_{n} \cdot g_{n}}{\Gamma}\right)\right),
$$

which is the sum of the bit-rates of the $\hat{N}$ subcarriers used for DMT transmission. In (1), $S N R_{n}=E_{n} \cdot g_{n}$ is the SNR per subcarrier, where $g_{n}$ represents the subcarrier SNR when unit energy is applied, $\Gamma$ is the difference (gap) between the SNR needed to achieve maximum (Shannon) capacity and the SNR to achieve this capacity at a given bit error probability, and $E_{n}$ is the allocated energy per subcarrier, subject to an energy constraint given by:

$$
\sum_{n=1}^{\hat{N}} E_{n}=E_{t o t} \text {. }
$$

$E_{t o t}$ is the fixed total available energy for transmission. The problem is now to find the optimum number of bits per subcarrier, and the corresponding energy distribution per subcarrier $E_{n}$, in order to maximize the bit-rate. From (1) and (2), it can be seen that $\hat{N}$, the number of subcarriers used to achieve maximum bit-rate, doesn't need to correspond to the total number of available DMT subcarriers $N$. Therefore, the optimal solution is not always to use all available subcarriers to transmit information.

The solution to this bit-rate maximization problem, based on the use of Lagrange multipliers, is commonly known as water-filling. In [5], Chow showed that this water-filling solution can be computed numerically for practical use by his proposed finite bit-loading algorithm. This algorithm is based on (1) and starts by discarding the subcarriers that are least energy-efficient from information transmission, and redistributing the energy to more efficient subcarriers to support higher data rates. The non-integer number of allocated bits per subcarrier are then rounded to the nearest integer and the corresponding energy is in- or decreased to support the newly-allocated 


\section{OWM2.pdf}

number of bits at the same performance. Chow's algorithm has been shown to achieve near-optimum performance [4],[5] and will be used in the following to compute rate-adaptive bit-loading for the DMT over MMF measurements.

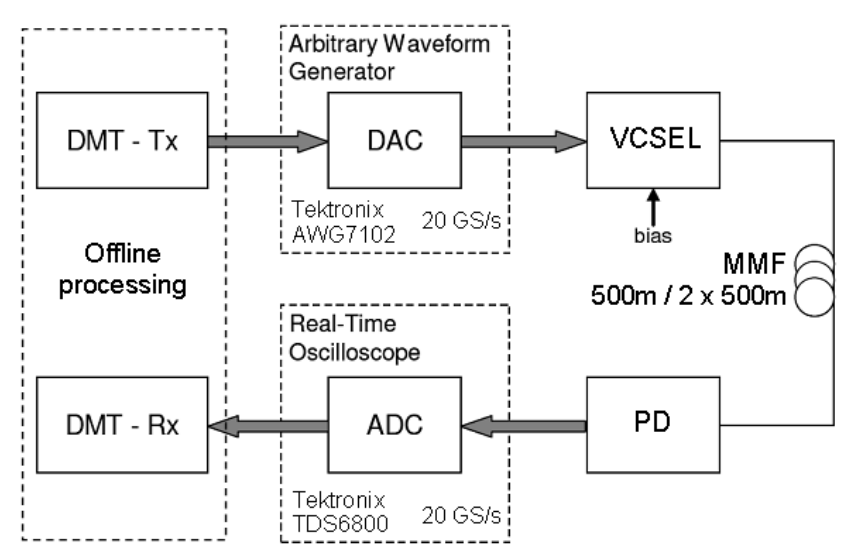

Fig. 1. Measurement setup for DMT over MMF transmission. Tx: transmitter; Rx: receiver; DAC: digital-to-analog converter; ADC: analog-to-digital converter; PD: photodetector.

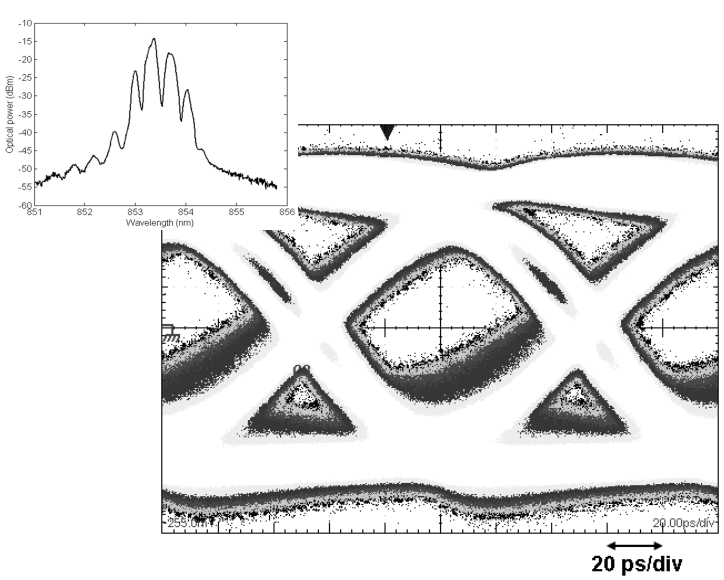

Fig. 2. Measured 10-Gb/s eye diagram after transmission over $1000 \mathrm{~m}$ of MMF using 850-nm VCSEL. Inset: Measured optical spectrum of VCSEL from $851 \mathrm{~nm}$ to $856 \mathrm{~nm}$.

\section{Experimental Results and Discussion}

Fig. 1 shows the setup of the DMT transmission system. The optical transmitter used is a commercial, analogdriven, 850-nm multimode VCSEL, specified for up to 10-Gb/s operation with on-off keying modulation. Two 500-m spools of MMF (MaxCap550, OM4, $4700 \mathrm{MHz} \cdot \mathrm{km}$ effective bandwidth at $850 \mathrm{~nm}$ ) were used for the experiments. The two spools are connected together in the case of transmission over a distance of $1000 \mathrm{~m}$. The photodetector (PD) with integrated electrical amplifier consists of a $25-\mu \mathrm{m}$ GaAs PIN diode, pigtailed to a 62.5 - $\mu \mathrm{m}$ MMF via a GRIN lens. The optical output power of the VCSEL is fixed at $-0.7 \mathrm{dBm}$ and the detected power levels after $500 \mathrm{~m}$ and $1000 \mathrm{~m}$ of MMF are $-1.9 \mathrm{dBm}$ and $-3.1 \mathrm{dBm}$ respectively. Fig. 2 depicts the measured 10-Gb/s eye diagram using the setup with $1000 \mathrm{~m}$ of MMF. The optical spectrum (from 851 to $856 \mathrm{~nm}$ ) of the VCSEL is shown in the inset, where the different modes can be clearly distinguished.
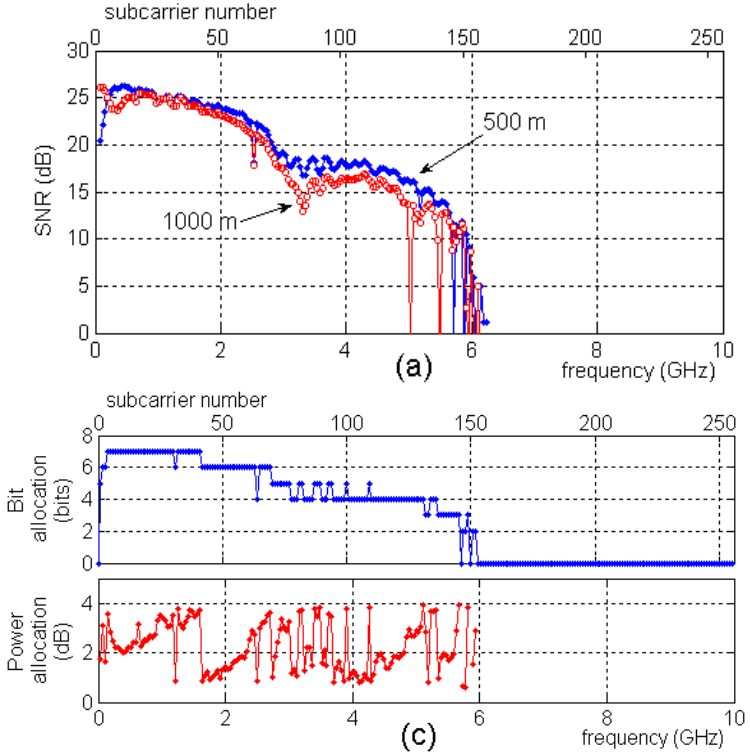
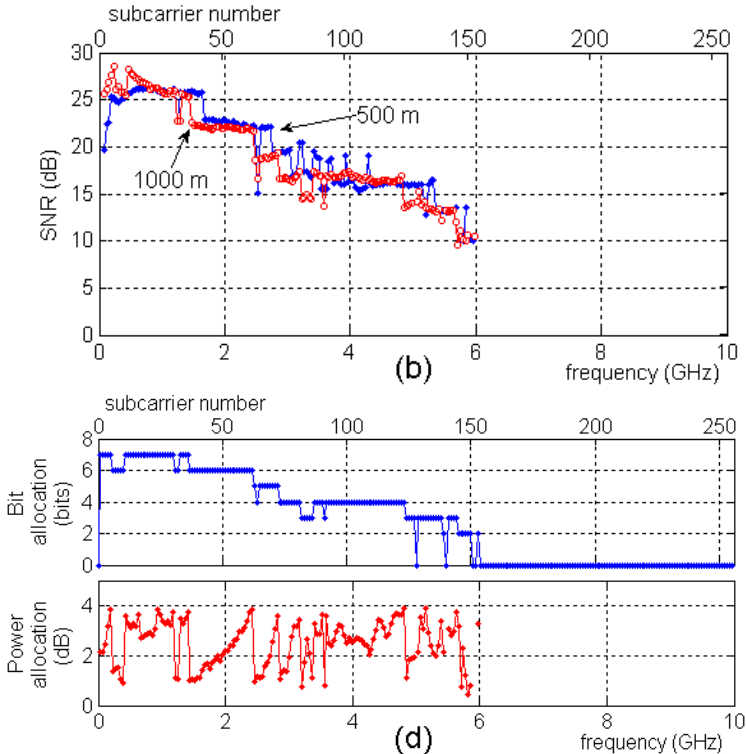

(d)

Fig. 3. (a) Evaluated SNR per subcarrier after transmission over $500 \mathrm{~m}$ and $1000 \mathrm{~m}$ of MMF, prior to bit-loading. (b) Resulting SNR per subcarrier, after bit-loading. (c) Bit-loading parameters for $500 \mathrm{~m}$ MMF. (d) Bit-loading parameters for $1000 \mathrm{~m}$ MMF. 


\section{OWM2.pdf}

For DMT transmission, a computer is used to emulate the digital DMT modulator and demodulator. An arbitrary waveform generator (AWG) is then used to generate the corresponding analog DMT time signal at a sampling speed of $20 \mathrm{GS} / \mathrm{s}$. At the receiver, the analog DMT signal after the PD is captured with a real-time oscilloscope at $20 \mathrm{GS} / \mathrm{s}$ and sent back to the computer for demodulation and evaluation. A total of 256 subcarriers are available for DMT transmission, ranging from 0 to $10 \mathrm{GHz}$. Prior to bit-loading, a pilot DMT signal is sent over the system to determine the available signal-to-noise ratio per subcarrier, as shown in Fig. 3a. It is apparent that the system bandwidth limits the transmission bandwidth to approximately $6 \mathrm{GHz}$. Fig. 3c and d show the results from Chow's bit-loading algorithm, for transmission over respectively $500 \mathrm{~m}$ and $1000 \mathrm{~m}$ of MMF. The desired bit-error-ratio (BER) is set to $1 \cdot 10^{-3}$, which corresponds to an SNR gap $\Gamma$ of approximately $7.2 \mathrm{~dB}$. The bit-loading results show that only 150 out of a total of 256 subcarriers should be used to achieve maximum bit-rate, where some subcarriers are allocated 7 bits of information (128-QAM modulation). Due to the power allocation, the measured SNR per subcarrier after bit-loading are stair-case-shaped as depicted in Fig. 3b.

Fig. 4 shows the transmitted and received electrical DMT signal spectra for transmission over $1000 \mathrm{~m}$ of MMF. The curve in Fig. 4c is obtained when the VCSEL is turned on with a fixed bias, without any modulation. This shows the relative intensity noise (RIN) spectrum of the transmission system, resulting from the competition of different modes of the VCSEL [6]. This RIN also affects the channel SNR, which can be noticed as a dip at approximately $3.5 \mathrm{GHz}$ in the evaluated SNR curves in Fig. 3a. Nevertheless, DMT with bit-loading adapts well to this loss of SNR. Fig. 5a and b show the BER per subcarrier after evaluation of 23000 received DMT symbols, equaling a total of 16 million bits. The total average BER for 500-m and $1000-\mathrm{m}$ transmission are $7 \cdot 10^{-4}$ and $1 \cdot 10^{-3}$ respectively. From the bit-loading parameters, it can be calculated that $30-\mathrm{Gb} / \mathrm{s}$ is achieved over $500 \mathrm{~m}$ and $28-\mathrm{Gb} / \mathrm{s}$ over $1000 \mathrm{~m}$ of MMF using DMT with bit-loading. After deduction of $1.5 \%$ of cyclic prefix, $2 \%$ of pilot symbols, and $7 \%$ of FEC overhead, the net transmission bit rate equals $27.2 \mathrm{~Gb} / \mathrm{s}$ over $500 \mathrm{~m}$ and $25.4 \mathrm{~Gb} / \mathrm{s}$ over $1000 \mathrm{~m}$ of MMF. Fig. 5c and d depict the highest received constellation diagrams employing 128-QAM after transmission over MMF, as an indication of the received signal quality.

\section{Conclusions}

$30-\mathrm{Gb} / \mathrm{s}(27.2-\mathrm{Gb} / \mathrm{s}$ net) transmission over $500 \mathrm{~m}$ and $28-\mathrm{Gb} / \mathrm{s}(25.4-\mathrm{Gb} / \mathrm{s}$ net) transmission over $1000 \mathrm{~m}$ of MMF are experimentally demonstrated with a commercial 850-nm multimode VCSEL and a commercial 25- $\mu \mathrm{m}$ photodetector with GRIN lens. This is achieved by DMT modulation combined with Chow's rate-adaptive bitloading algorithm for maximizing the bit-rate.

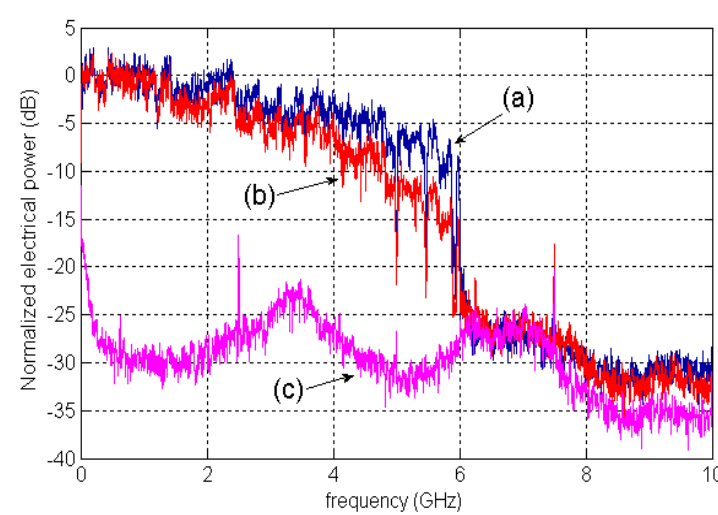

Fig. 4. Measured electrical spectra for (a) sent DMT signal, electrical back-to-back; (b) received DMT signal, after 1000 m MMF; (c) relative intensity noise of VCSEL.
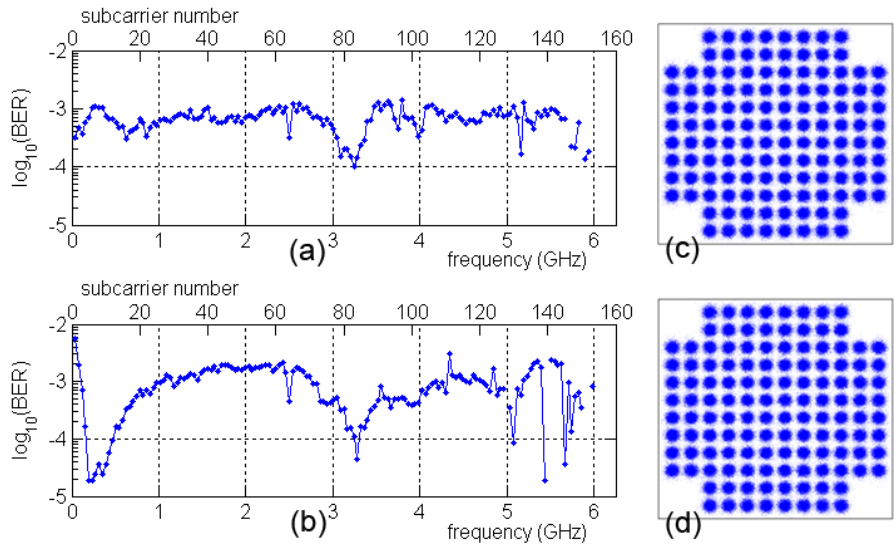

Fig. 5. Measured BER per subcarrier for: (a) $500 \mathrm{~m} \mathrm{MMF}$, total averaged $\mathrm{BER}=7 \cdot 10^{-4}$, (b) $1000 \mathrm{~m} \mathrm{MMF}$, total averaged $\mathrm{BER}=1 \cdot 10^{-3}$. (c)

Received 128-QAM constellations after 500 m MMF, (d) 1000 m MMF.

\section{References}

[1] S.C.J. Lee, et al., "24-Gb/s Transmission over 730 m of Multimode Fiber by Direct Modulation of an 850-nm VCSEL using Discrete Multi-tone Modulation,” OFC 2007, Paper PDP6.

[2] J. M. Tang and K. A. Shore, "Maximizing the Transmission Performance of Adaptively Modulated Optical OFDM Signals in MultimodeFiber Links by Optimizing Analog-to-Digital Converters," J. Lightw. Technol., vol. 25, no. 3, pp. 787-798, Mar. 2007.

[3] B. Charbonnier, et al., ECOC 2008, Paper We.3.F.5.

[4] J.M. Cioffi. (2008, Jun. 1). Advanced Digital Communication, Course Reader [Online]. Available: http://www.standford.edu/class/ee379c [5] P.S. Chow, J.M. Cioffi, and J.A.C. Bingham, "A Practical Discrete Multitone Transceiver Loading Algorithm for Data Transmission over Spectrally Shaped Channels," IEEE Trans. Commun., vol. 43, no.2, Feb. 1995. 